\title{
Effect of Special Shaped Column on Lateral Load Resistance Capacity of Reinforced Concrete (RC) Building
}

\author{
Atickur Rahaman ${ }^{1, ~ *, ~ A s i f ~ M o s t a f a ~ A n i k ², ~ N . ~ H . ~ M . ~ K a m r u j j a m a n ~ S e r k e r ~}{ }^{1}$ \\ ${ }^{1}$ Department of Civil Engineering, Rajshahi University of Engineering \& Technology, Rajshahi, Bangladesh \\ ${ }^{2}$ Axis Design Consultants LTD, Dhaka, Bangladesh

\section{Email address:} \\ atick.13.ruet@gmail.com (A. Rahaman), a.m.aanikce@gmail.com (A. M. Anik), kserker@gmail.com (N. H. M. K. Serker) \\ ${ }^{*}$ Corresponding author
}

\section{To cite this article:}

Atickur Rahaman, Asif Mostafa Anik, N. H. M. Kamrujjaman Serker. Effect of Special Shaped Column on Lateral Load Resistance Capacity of Reinforced Concrete (RC) Building. American Journal of Civil Engineering. Vol. 6, No. 5, 2018, pp. 147-153.

doi: $10.11648 /$ j.ajce. 20180605.12

Received: August 9, 2018; Accepted: October 29, 2018; Published: November 26, 2018

\begin{abstract}
Column plays very important role in reinforced concrete building as total load is transferred through column. When rectangular columns are used in structure, columns can protrude out of the walls and corners which reduce aesthetic view of structure. Concrete structures with specially shaped columns has been found out as a solution of this problem. Not only for aesthetical point of view but also for structural aspect, specially shaped columns perform well. The aim of this study is to evaluate the comparative lateral load resistance capacity of buildings with rectangular columns and buildings with specially shaped columns. Four different buildings (i.e. 6 storey, 10 storey, 15 storey and 20 storey) are analysed with conventional rectangular columns and same buildings are analysed with specially shaped (i.e. L, Tee, cross) columns with same equivalent cross section area as of rectangular columns. In this paper, at first, the proposed buildings are analysed with linear static analysis and Secondly, linear dynamic analysis. From analysis results, it has been found that maximum storey displacements of all building models i.e. $6,10,15 \& 20$ storeys are under acceptable limit for both rectangular and special shaped columns. For rectangular shaped column building, displacement increases $11.78 \%, 8.83 \%$ \& $34.84 \%$ \& $5.51 \%$ respectively for $6,10,15 \&$ 20 storeys building compared with building with special shaped columns. After analysis and comparison it is concluded that the buildings with specially shaped columns perform better under lateral load conditions than the buildings with conventional rectangular columns under the same loadings.
\end{abstract}

Keywords: Special Shaped Column, Rectangular Column, Seismic Analysis, Static Analysis, Dynamic Analysis

\section{Introduction}

Now-a-days, the architects often prohibit the widths of the columns so that more free space is available and for the good aesthetic look of the building without columns protruding out of the walls and corners.

Concrete structures with non-rectangular specially shaped thin columns found out as an alternative to the above said problem and it is found out that non-rectangular specially shaped thin columns performs well structurally with all analysis results within acceptable limits [1]. This kind of structure satisfies spatial requirements of corners as well as intersection of corners so that no visible edges or prominent column would appear in the buildings [2]. This expands the actual usable floor area and more furniture can be placed into the buildings. For this reason, frame structure with specially shaped column is suitable blooms, especially for villa and multi-storey buildings [3].

Previous research showed the buildings which have nonrectangular specially shaped thin columns performs better under seismic and wind load conditions than the building with conventional rectangular columns under the same loadings [4]. This paper explains the behaviour of buildings with Rectangular columns and buildings with specially shaped columns and values of various parameters like story drift, story displacement, story stiffness etc. on the basis of 
lateral loads.

\subsection{Specially Shaped Columns}

In the RCC buildings, columns are structural elements which are predominantly subjected to axial compressive forces, moments, and transfers total load from the super structure to sub-structure. Various shapes of the columns are used. Some common shapes are square, rectangular, circular columns and some special shapes of columns are L-shaped, T- shaped and plus (+) shaped columns as shown in figure 1 which are not commonly used but gives more indoor space than commonly used shapes of columns. Special shaped columns avoid prominent corners in a room which increases usable floor area [5].

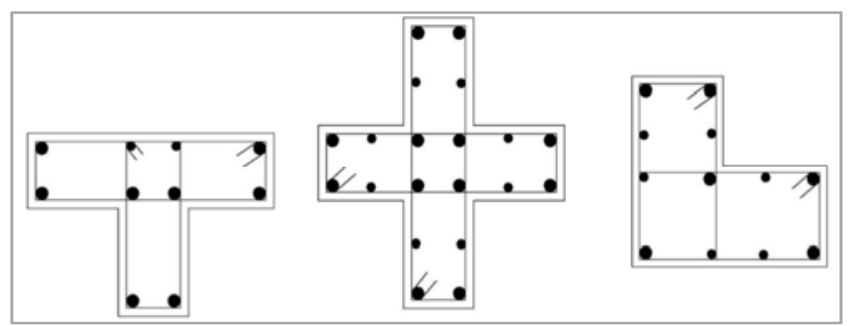

Figure 1. Specially shaped $(T,+, L)$ columns with Longitudinal and lateral reinforcement.

The reinforced concrete structure system with specially shaped columns is a system widely adopted in residential structures due to no exposed beams and columns in the room [6]. The feasibility and convenience of reinforced concrete (RC) frame with special shaped columns in structural design and its favourable service make it widely used in construction industry [7].

\subsection{Objectives}

The main objectives of this study are to evaluate the performance of building with special shaped column. Followings are the specific objectives of this study.

(1) To study the behaviour of the building under lateral loads like seismic and wind loads.

(2) Determination of deflections, storey drifts, storey stiffness and storey overturning moment of the buildings under wind and seismic conditions.

(3) To compare the performance of the special shaped column building with building of rectangular columns.

\section{Methodology}

This study is carried out by considering a rectangular plan building with total width of $51 \mathrm{ft}$ (Y-direction) and total length of $50 \mathrm{ft}$ (X-direction). The same building is analysed with specially shaped (L, T, + plus) columns with four different models of $6,10,15,20$ storeys and the economical sizes of columns are determined by trial and error with E-Tabs software. ETABS software is used for static and dynamic analysis both. Again the same building is analysed with conventional rectangular columns of sizes with same equivalent areas of special shaped columns. Dimension of beams and columns as well as other properties of the building and loading data are specified in table $1 \& 2$.

Table 1. Geometrical dimensions of the building and material properties.

\begin{tabular}{lll}
\hline Member properties & & \\
\hline Slab & Thickness & $6 "$ \\
Column & Rectangular Shaped & $13 " * 16 *$ \\
& T-Shaped & $21 " * 26 " * 5 "$ \\
& L-Shaped & $23 " * 24 " * 5 "$ \\
& Cross Shaped & $22{ }^{*} * 25 " * 5$ \\
Beam & Grade Beam & $16 " * 15 "$ \\
& Floor Beam & $15 " * 14 "$ \\
& Roof Beam & $13 " * 12 "$ \\
Concrete & Grade of concrete & $3 \mathrm{ksi}$ \\
Steel & Grade of steel & $60 \mathrm{ksi}$ \\
\hline
\end{tabular}

Table 2. Loading data.

\begin{tabular}{ll}
\hline PARAMETERS & Values \\
\hline Live load & $50 \mathrm{psf}$ \\
Roof live load & $10 \mathrm{psf}$ \\
Floor finish load & $20 \mathrm{psf}$ \\
Wall load & $0.5 \mathrm{k} / \mathrm{ft}$. \\
Parapet wall load & $.08 \mathrm{k} / \mathrm{ft}$. \\
Density of concrete & $150 \mathrm{lb} . / \mathrm{ft} 3$ \\
Density of brick & $110 \mathrm{lb} . / \mathrm{ft} 3$ \\
Wind velocity & $96 \mathrm{mph}$ \\
Seismic zone & $\amalg$ \\
Site co-efficient & 1.2 \\
Importance factor & 1 \\
Response reduction factor & 8 \\
\hline
\end{tabular}

The methods of analysis used for the present study are:

(1) Equivalent Static Force Analysis

(2) Response Spectrum Analysis

\subsection{Equivalent Static Force Analysis}

The equivalent static force analysis for an earthquake is an exceptional concept which is used in earthquake resistant design of structure. This concept is useful since it converts a dynamic analysis into a partly static \& dynamic analysis to evaluate the maximum displacements produced in the structure because of earthquake due to ground motion [8]. For earthquake resistant design of structures, only these maximum displacements are of interest, but not the time history of stresses. Equivalent lateral force for an earthquake is defined as a set of static lateral forces which produces the similar peak responses of the structure as that have been produced in the dynamic analysis of the building under the similar ground motion [9]. This concept has drawback since it uses only a single mode of vibration of the structure.

\subsection{Response Spectrum Method}

In this concept the multiple modes of vibration of a structure can be used. This analysis can be used in many building codes for all except for simple or complex 
structures. The vibration of a building is defined as the combination of many special modes that are in a vibrating string corresponding to the "harmonics" [10]. Computer aided structural analysis is used to determine these mode shapes for the structure. For every mode shape, from design spectrum responses are studied, with the help of parameters such as modal participation mass and modal frequency, and then they are combined to provide an evaluation of the total responses of the structure [11].

Following cases are considered for this project: Case1: Six storey building with rectangular columns;

Case 2: Six storey building with special shaped columns;

Case3: Ten storey building with rectangular columns;

Case4: Ten storey building with special shaped columns;

Case 5: Fifteen storey building with rectangular columns;

Case6: Fifteen storey building with special shaped columns;

Case7: Twenty storey building with rectangular columns and

Case8: Twenty storey building with special shaped columns.

\section{Results and Discussion}

\subsection{Storey Displacement}

Maximum story displacement for both rectangular and special shaped columns are obtained from equivalent static force method. Here, earthquake load in $\mathrm{X}$ direction is considered for analysis.

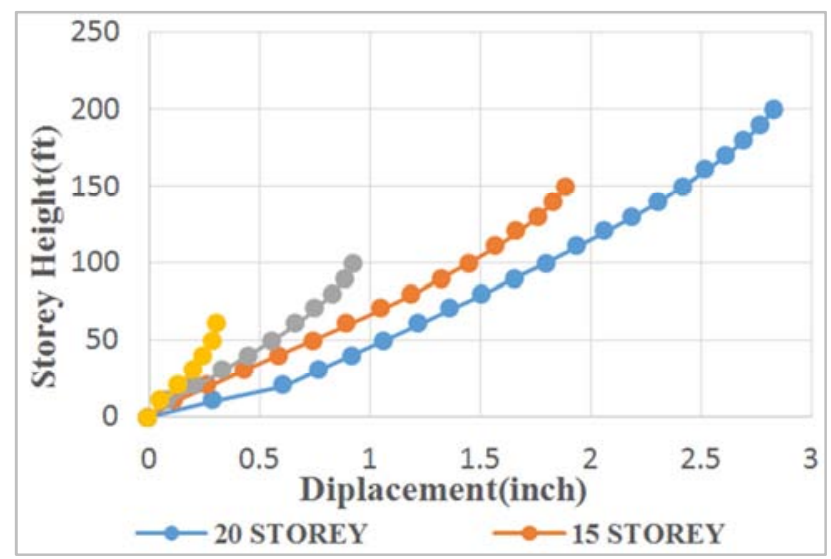

Figure 2. Variation of story displacement using rectangular columns with respect to story height.

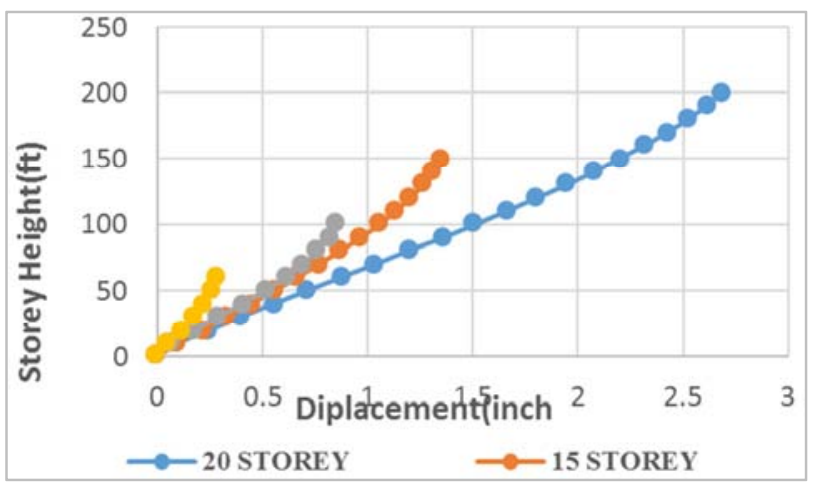

Figure 3. Variation of story displacement using special columns with respect to story height.
From analysis results, it has been found that maximum storey displacements of all building models i.e. 6, 10, 15 \& 20 storeys are under acceptable limit for both rectangular and special shaped columns. For rectangular shaped column building, displacement increases $11.78 \%, 8.83 \%$ \& $34.84 \%$ \& $5.51 \%$ respectively for $6,10,15 \& 20$ storeys building compared with building with special shaped columns. Another analysis is done for displacement considering wind load in $\mathrm{X}$ direction for same dimension, material properties \& loading.

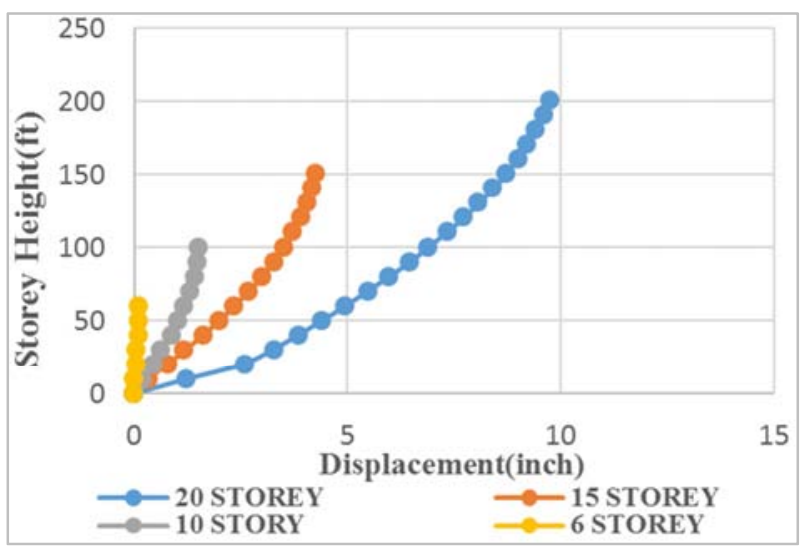

Figure 4. Variation of story displacement using Rectangular columns with respect to height.

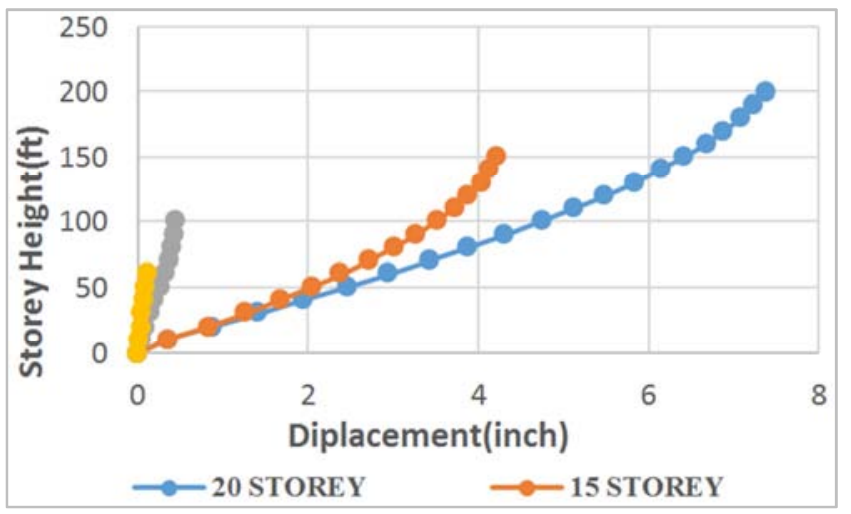

Figure 5. Variation of story displacement using special columns with respect to story height.

From analysis for both condition lateral displacements for $6,10,15 \& 20$ storeys building are not in safe. For rectangular shaped column building, displacement increases $11.81 \%, 0.91 \% \& 31.91 \%$ respectively for $6,15 \& 20$ storeys building. And for 10 storeys building displacement increases about two times more than the buildings with specially shaped columns.

\subsection{Story Drift}

Maximum story drift for both rectangular and special shaped columns are obtained from equivalent static method. Here earth quake load in $\mathrm{X}$ direction is considered for analysis. 


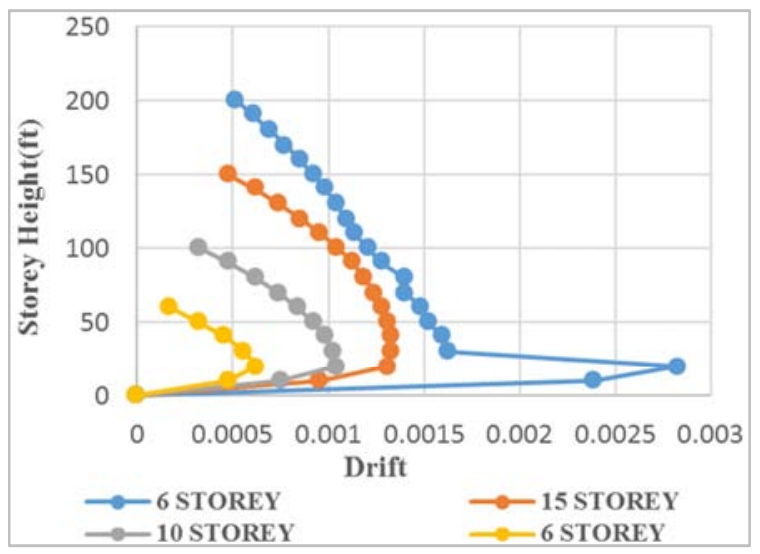

Figure 6. Variation of story drift using rectangular columns with respect to story height.

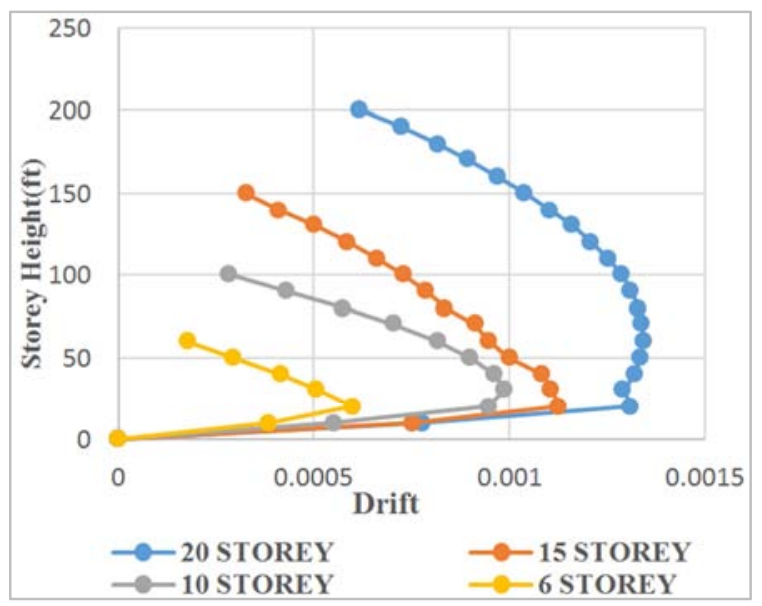

Figure 7. Variation of story drift using special columns with respect to story height.

For rectangular shaped column building, story drift increases $11.11 \%$ \& $18.81 \%$ respectively for 10 \& 15 storeys building. And for 20 storeys building, story drift increases about two times more than the building with special shaped column.

Another analysis is done for story drift considering wind load in $\mathrm{X}$ direction.

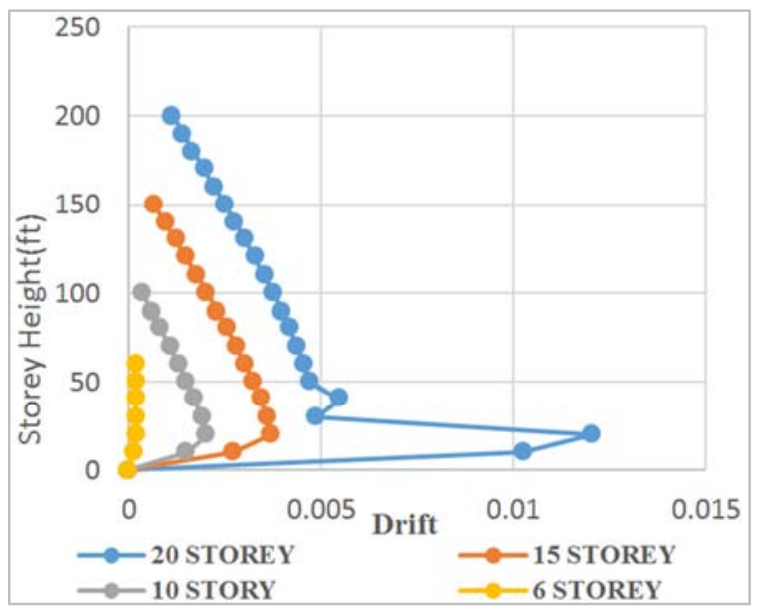

Figure 8. Variation of story drift using rectangular columns with respect to story height.

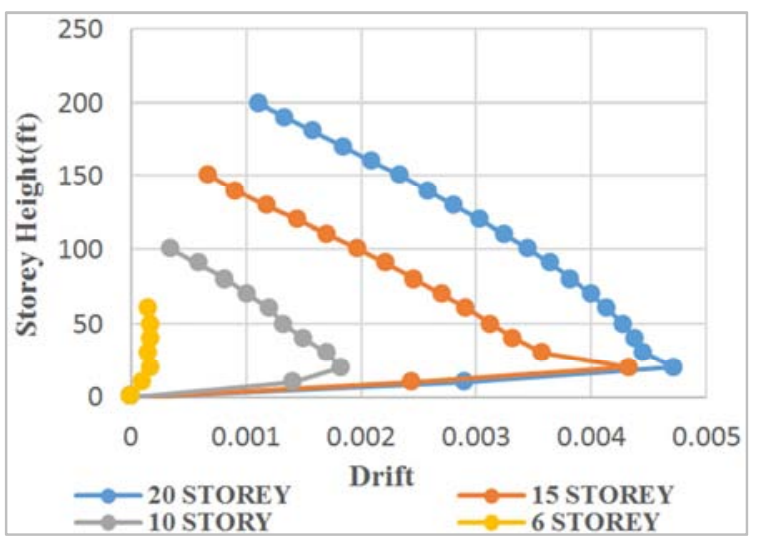

Figure 9. Variation of story drift using special columns with respect to story height.

For rectangular shaped column building, story drift increases $19.44 \%$ for 10 Storeys building. And for $15 \& 20$ storeys building, story drift increases about four times \& 2.5 times respectively more than the buildings with specially shaped columns.

\subsection{Story Stiffness}

According to BNBC code 2015, A soft story is one in which the lateral stiffness is less than $70 \%$ of that in the story above or less than $80 \%$ of the average lateral stiffness of the three story above irregularity. An extreme soft story is defined where its lateral stiffness is less than $60 \%$ of that in the story above or less than $70 \%$ of the average lateral stiffness of the three story above irregularity. In this study story stiffness observed from static analysis and load case for earthquake in $\mathrm{x}$ direction is considered for determining story stiffness.

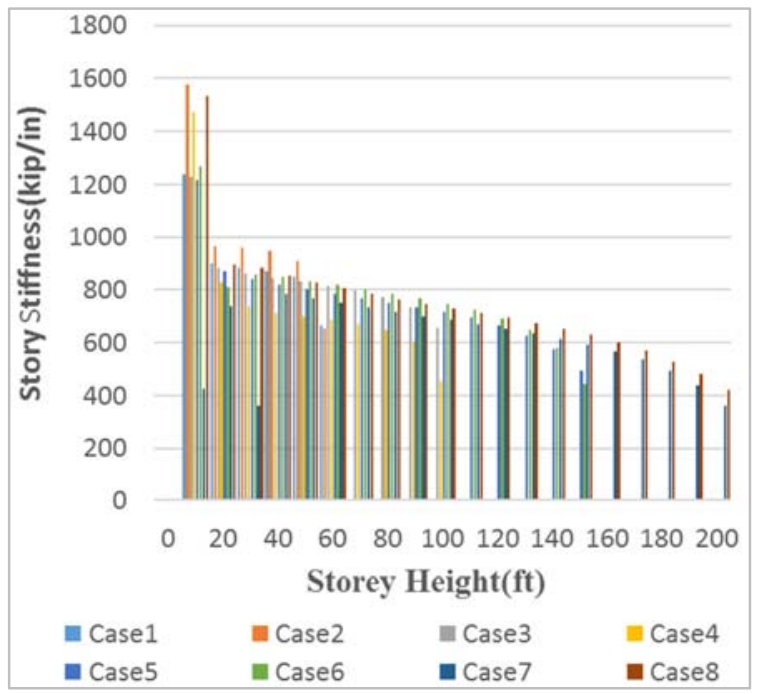

Figure 10. Variation of story stiffness for various cases.

Another analysis is done for story stiffness considering wind load in $\mathrm{X}$ direction. 


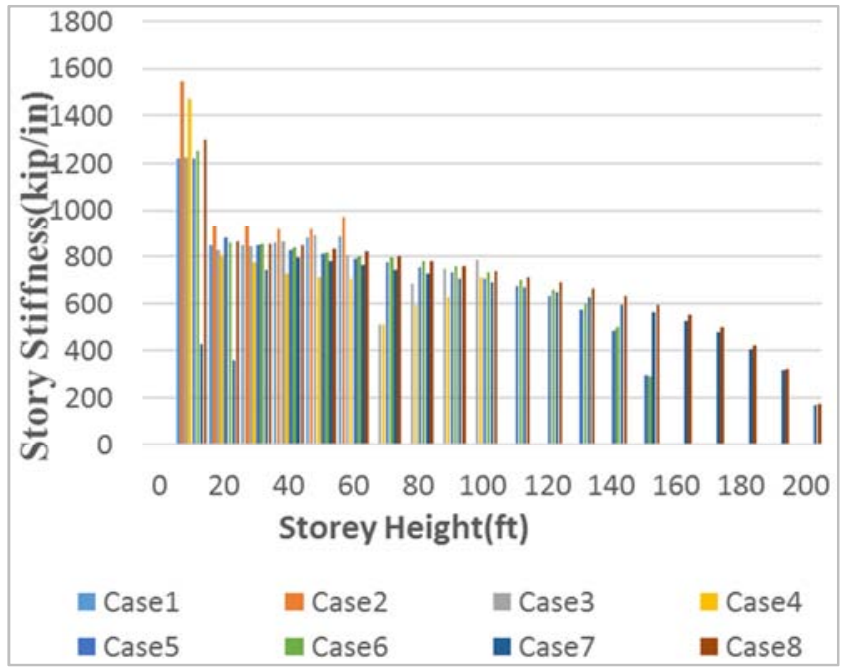

Figure 11. Variation of story stiffness for various cases.

In this study, there is no soft story except 20 storey building using rectangular shaped columns. Lateral stiffness decreases for rectangular shaped building.

\subsection{Overturning Moment}

An overturning moment is quite literally the force that is attempting to overturn an object. The resisting moment must be at least equal to the overturning moment. For analysis, storey overturning moment in $\mathrm{Y}$-direction is considered for earthquake load.

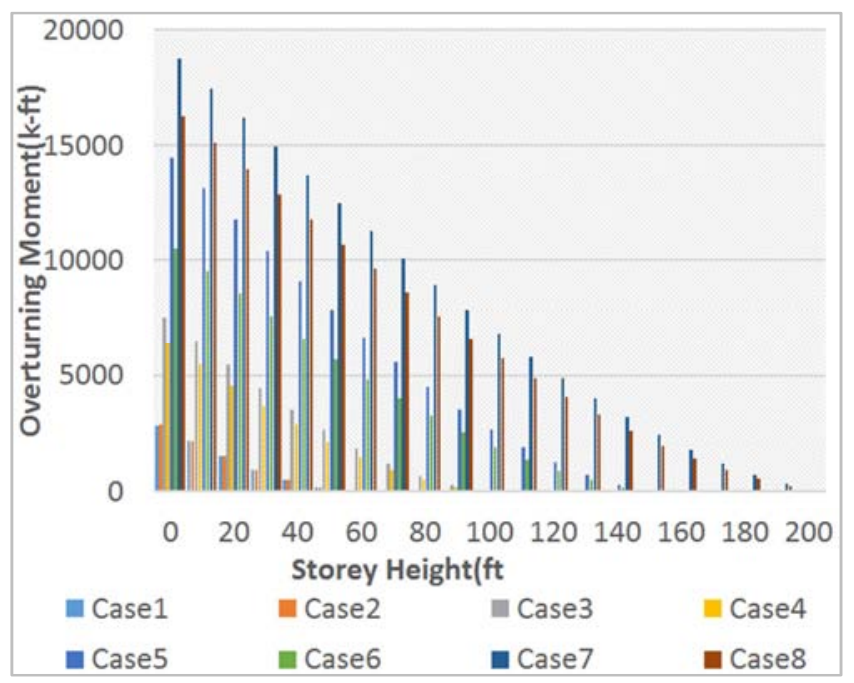

Figure 12. Variation of storey overturning moment for various cases.

The above figure shows that the overturning moment varies oppositely with height of the storey. For all cases, Storey overturning moment decreases with increase in height of the storey. In case of rectangular shaped columns building, it produces higher moment than special shaped columns building. As special shaped column produce less moment than rectangular columns, it requires less reinforcement to resist overturning moment. So it will be more economical than rectangular shaped column building.

\subsection{Fundamental Time Periods}

Fundamental time period is the time taken by the building to undergo a cycle of to and fro movement. In this study fundamental time period determined from modal ana.

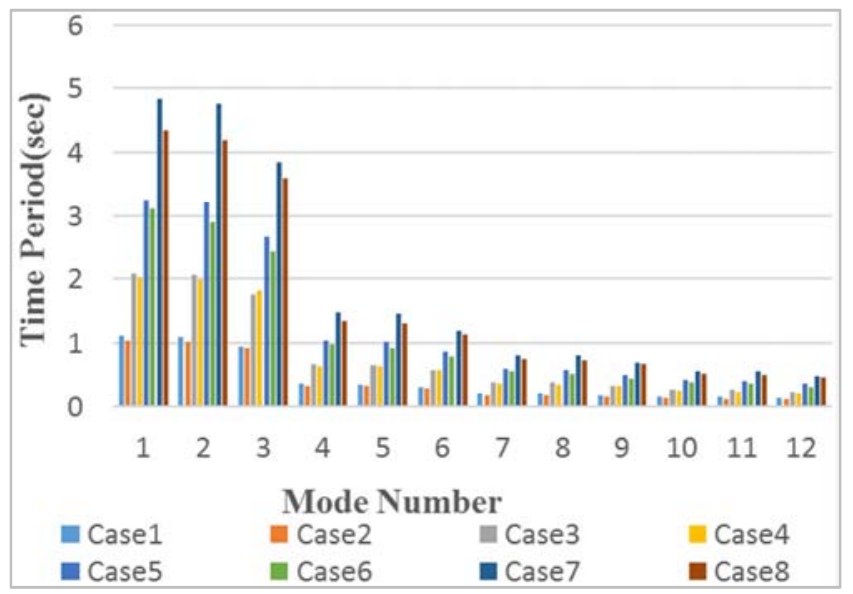

Figure 13. Variation of fundamental time period for various cases.

\subsection{Different Mode Shapes for Different Building Cases}

It is observed that fundamental time period is increasing due to using rectangular shaped columns. As fundamental time period increases, it decreases the overall stiffness of the building. On the other hand fundamental time period decrease due to using special shaped columns. As fundamental time period decreases, it increases stiffness of the building.
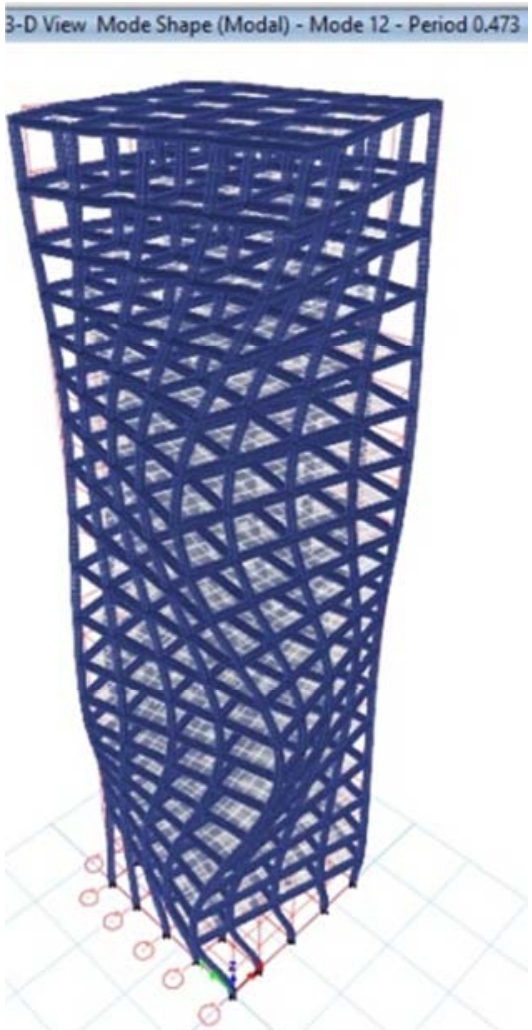

Figure 14. Mode shapes for 12th mode for twenty storey building using rectangular columns. 


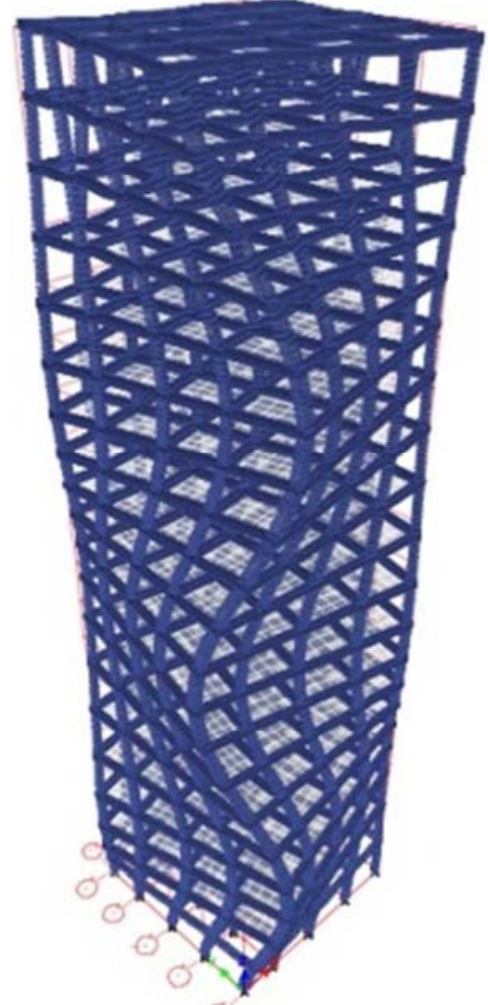

Figure 15. Mode shapes for 12th mode for twenty storey building using special shaped columns.

\section{(3) 3 -D View Mode Shape (Modal) - Mode 12- Period 0.355}

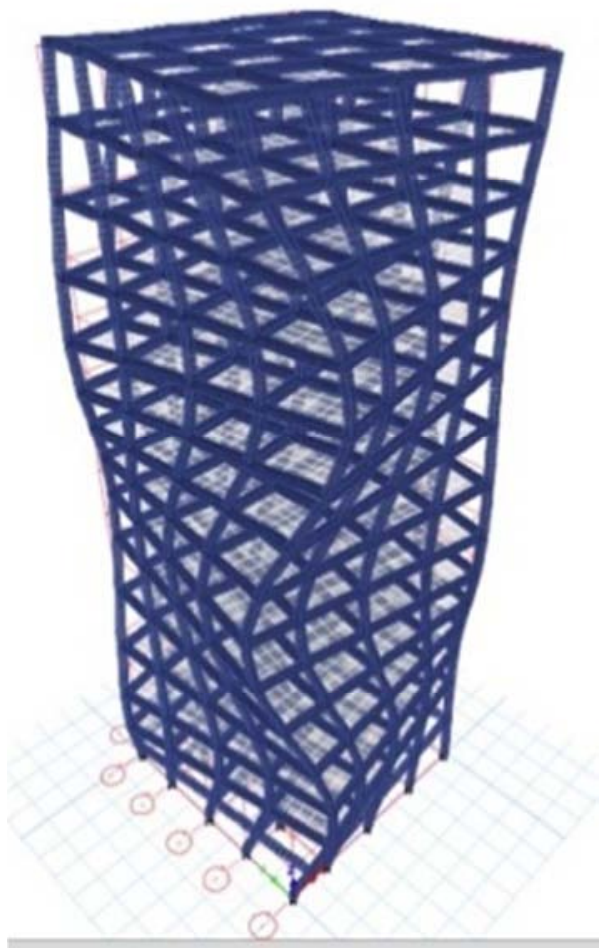

Figure 16. Mode shapes for 12th mode for fifteen storey building using rectangular Columns.

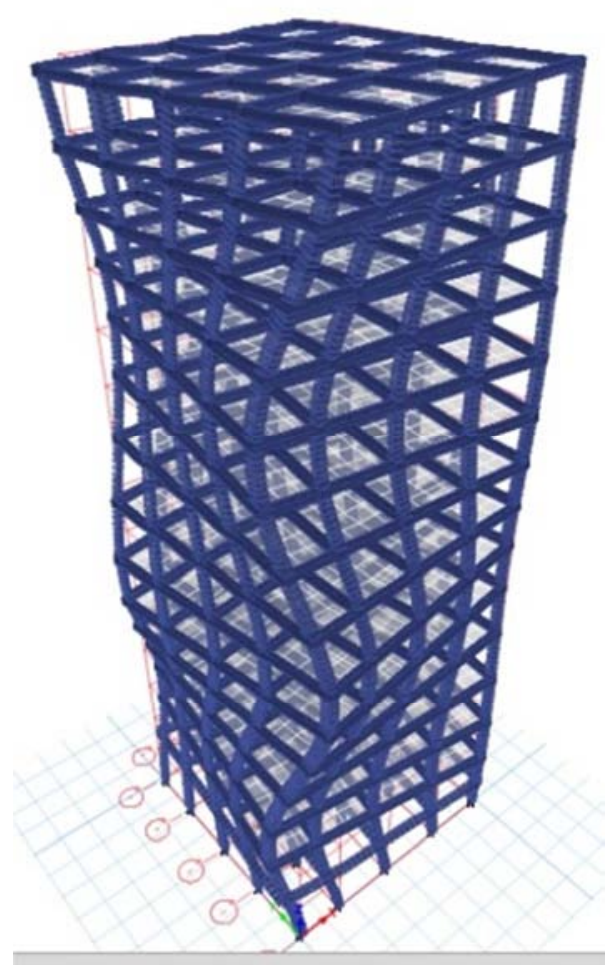

Figure 17. Mode shapes for 12th mode for fifteen storey building using special shaped columns.

\section{Conclusions}

After the detailed comparative study, as per engineering knowledge and best practices it is been established that the building with non-rectangular specially shaped thin columns performs better under seismic and wind load conditions than the building with conventional rectangular columns under the same loadings. The following conclusions were drawn based on observations and findings from the analysis described in this paper.

i Maximum story displacement and story drift for both seismic and wind load condition is more in rectangular column building compared to special column building.

ii Story stiffness is less in rectangular column building compared to special column building.

iii Fundamental time period of rectangular column building is greater than special building.

It is also been concluded that buildings with non-rectangular columns will be more economical and user friendly with good aesthetics. The outcome of this project is that the cost of construction of multi-storeyed buildings like apartments, hotels, offices etc. would be less with more free space with column free look is available for the dwellings.

\section{Acknowledgements}

I would like to express my profound sense of deepest gratitude to my guide and motivator Dr. Kamrujjaman Serker, 
professor, Civil Engineering Department, Rajshahi University of Engineering \&Technology, Rajshahi for his valuable guidance, sympathy and co-operation for providing necessary facilities and sources during the entire period of this research work. I am also immensely grateful to Asif Mostafa Anik for sharing his pearl of wisdom and helping me in learning FEM analysis with best practices that are followed in the industry and his intellectual contribute to this research.

\section{References}

[1] Yang, Pu. Tang, Jian. Chen, Mingdi, and Huang, Zongming. (2005). Analysis on Seismic Capacity for RC Specially Shaped Columns in Different Horizontal Direction. Journal of Chongqing University $28: 8,117-121$

[2] Yang, Pu. Tang, Jian and Huang, Zongming (2006) "Study on Seismic Performance of regular RC frame with special shaped columns" Earthquake engineering and engineering vibration26: 3, $145-147$

[3] Faria Aseem (2016) "Evaluation of Suitability of NonRectangular Specially Shaped Thin Columns in Multi Storeyed Buildings using E-TABS Software" International Journal of Multidisciplinary Engineering in Current Research, Volume 1, Issue 1, September 2016.

[4] Pu Yang, Hongxing Liu and Zongming Huang(2008), “A Comparison of seismic behaviour between Specially Shaped Column frame structure and Rectangular Column frame structures" proceeding of the 14th World Conference on Earthquake Engineering, Beijing, China, October 12-17, 2008.

[5] Chen, Tao. Chen, Juan and Huang, Zongming. (2007), Effects of different load paths on seismic behaviour of L-shaped reinforced concrete columns. Journal of Earthquake Engineering and Engineering Vibration 27: 3, 58-63.

[6] Bedabrata Bhattacharjee (2007), "Computer aided analysis and design of multi-storeyed buildings" Bachelor Thesis, National Institute of Technology Rourkela, India.

[7] Tiecheng Wang, Xiao Liu and Hailong Zhao (2014),"Experimental Study of the Seismic Performance of LShaped Columns with 500MPa Steel Bars" proceeding of the Hindawi Publishing Corporation The Scientific World Journal Volume 2014, Article ID 105826.

[8] S. N. Sinha, Handbook of Reinforced Concrete Design", Tata McGraw Hill, New Delhi, pp 93-94 and pp. 237-371.

[9] U. H. Varyani, "Structural design of multi-storeyed buildings", Second Edition, South Asian Publishers, New Delhi.

[10] Li, Jie. Xiao, Jianzhuang and Chen, Jianbing. (2002)., Experimental study on RC structures with special-shaped Columns. Journal of Civil Engineering35: 3, 7-12.

[11] Wang C. J.(2015), The research and application of concrete structure with special-shaped columns, China Concrete and cement products, (10) 49-52. 